\title{
Comparative Analysis of Routing Protocols in Mobile Ad-Hoc Networks (MANETs)
}

\author{
Parul Aggarwal \\ Research Student, Department of Computer \\ Engineering \\ Punjabi University, Patiala \\ Punjab-147002 (India)
}

\author{
Himanshu Aggarwal, Ph.D \\ Professor, Department of Computer \\ Engineering \\ Punjabi University, Patiala \\ Punjab-147002 (India)
}

\begin{abstract}
A mobile ad-hoc network (MANET) is a collection of mobile nodes that is said to be connected through a wireless medium forming rapidly changing topologies. Mantes are infrastructure less in nature and can be set up anytime, anywhere. In this paper, a survey has been conducted of protocol properties of various MANET routing algorithms and analyzed them. The routing algorithms considered in the paper are said to be classified into two categories proactive (table driven) and reactive (on demand). The algorithms considered in this paper are AODV, DSDV and DSR. The comparison among these routing protocols is based on the various protocol property and category parameters.
\end{abstract}

\section{General Terms}

MANET Routing Protocols, Comparison

\section{Keywords}

MANET, Routing Protocols, Energy Efficiency, Comparison, AODV, DSDV, DSR

\section{INTRODUCTION}

A network is an assemblage of people or systems or organizations who are considered to be together as being related in some way or the other, that tend to contribute their information collectively for their business purpose which can be done as wired or wireless.

A mobile ad-hoc network (MANET) is said to be a collection of wireless mobile nodes that dynamically establishes the network in the absence of fixed infrastructure. Ad-hoc is known to be an imparted mode in the system that allows computers to directly interchanged information with each other without a router. In Latin, the word ad-hoc refers to "for this" meaning "for this special purpose". One of the distinctive features of MANET is each node must be able to act as a router to find out the optimal path to forward a packet. As nodes may be mobile, entering and leaving the network, the topology of the network will change continuously. To provide end-to-end [5] communication throughout the network, peer hosts cooperate with each other to handle network functions, such as packet routing.

One of the most important research areas in the MANETs is to establishing and maintaining the ad-hoc network through the use of routing protocols. Ad-hoc routing protocols can be divided into two categories: proactive routing protocols and reactive routing protocols. Proactive (table-driven) routing protocol is said to be an approach where each of the router can build its own routing table based on the information that each router or node can learn by exchanging information among the network's routers. Reactive (on-demand) routing protocol is an approach where the routing process needs to discover a route whenever a packet arrives from a source and needs to be delivered to a destination. A classification of MANET routing protocols is shown in Figure 1.1.

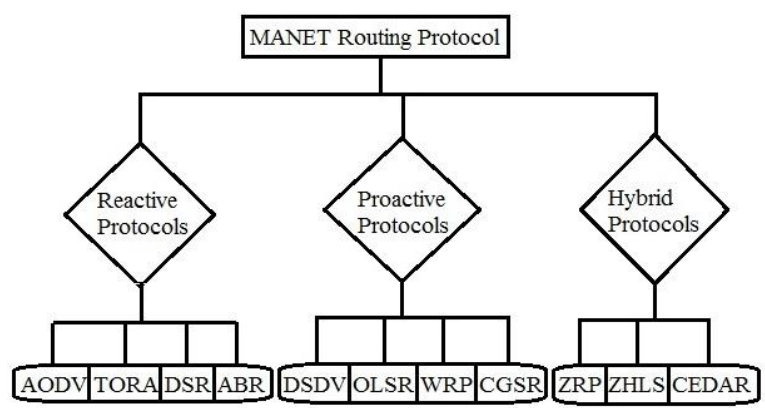

Figure1.1: Classification of MANET routing protocols

There are many routing protocols available. This paper considers AODV, DSDV and DSR for analysing their performance comparisons based on various properties and metrics.

The rest of the paper is organized as follows. Section II presents the categories of routing protocols in MANETs and their brief comparison. Section III describes the protocols. Section IV presents the comparison among some protocols. Section V concludes the paper.

\section{CATEGORIES OF ROUTING PROTOCOLS IN MANETS}

Re-active routing protocols [1] are source-initiated or on demand. It means that whenever a message is sent it first has to discover a way by searching the entire network. These routing protocols were made to abate the stress in proactive protocols by maintaining the information that will be used for active routes only. This may mean that the routes may be determined and maintained only for nodes that require sending data to a particular destination. Route discovery mostly occurs by flooding a route request packets through the network. When a node that has a route to the destination (or the destination itself) is reached a route reply is sent back to the source node using link reversal if the route request has travelled through bidirectional links or by piggy-backing the route in a route reply packet via flooding. Main Aspects of these protocols is: communication with low-overhead, finding the short path and balancing the overload. Reactive protocols [7] may be categorized into two ways: source routing and 
hop-by-hop routing. In the former category i.e. source routing on-demand routing protocols, each data packet contains the complete source to destination address. So, each node that is in between, forwards these packets according to the information kept in the header of each packet. This means that the nodes which are in-between do not need to keep up-todate routing information for each active route in order to advancing the packet towards the destination. Some examples of reactive protocols are: DSR, AODV, TORA etc.

Pro-active routing protocols [1] are table-driven. These kind of routing protocols maintain the routing information even before it is needed. Every node in the network gives the routing information to every other node in the network. Information of the routes is generally kept in the routing tables and is periodically updated whenever there is a change in the network topology. Pro-active routing protocols try to maintain consistent and up-to-date routing information from each node to every other node in the network. These protocols are not apt for larger networks, due to the fact that they need to maintain node entries for every node in the routing table of every node. This is the reason why more overhead occurs in the routing table which leads to consumption of more bandwidth [7]. Some examples of Proactive protocols are: DSDV, WRP, CGSR, OLSR etc.

Hybrid Routing Protocols [7] are the protocols which are a combination of the two routing protocols i.e. proactive and reactive routing protocols. It merges the merits of proactive and reactive routing protocols to overcome their demerits. Generally, hybrid routing protocols for typical mobile ad-hoc networks exploit hierarchical network architectures. A proper proactive routing approach and reactive routing approach is exploited in different hierarchy levels in the network, respectively [15]. Some examples of hybrid routing protocols are: ZRP, ZHLS, HARP etc.

\subsection{Desirable properties of MANETs}
a. Loop free
b. Demand based operation
c. Unidirectional link support
d. Security
e. Power conservation
f. Multiple routes
g. Distributed operation
h. Quality of support service

\subsection{Some differences between reactive and proactive routing protocols}

A general comparison [6] between the two categories of protocols is given in the table 2.1 .

Table 2.1: Comparison of two categories of protocols

\begin{tabular}{|l|l|l|}
\hline Parameters & On-demand & Table-driven \\
\hline $\begin{array}{l}\text { Availability of } \\
\text { routing } \\
\text { information }\end{array}$ & $\begin{array}{l}\text { Available when } \\
\text { needed } \\
\text { Routing } \\
\text { philosophy }\end{array}$ & $\begin{array}{l}\text { Always available } \\
\text { when needed }\end{array}$ \\
\hline $\begin{array}{l}\text { Routing } \\
\text { Overhead }\end{array}$ & Low flat, & $\begin{array}{l}\text { Mostly except for CGSR } \\
\text { High }\end{array}$ \\
\hline
\end{tabular}

\begin{tabular}{|l|l|l|}
\hline $\begin{array}{l}\text { Periodic route } \\
\text { updates }\end{array}$ & Not required & Required \\
\hline $\begin{array}{l}\text { Coping with } \\
\text { mobility }\end{array}$ & $\begin{array}{l}\text { Use localized } \\
\text { route discovery } \\
\text { as in ABR and } \\
\text { SSR }\end{array}$ & $\begin{array}{l}\text { Inform other } \\
\text { nodes to achieve } \\
\text { a consistent } \\
\text { routing table }\end{array}$ \\
\hline $\begin{array}{l}\text { Signalling } \\
\text { traffic } \\
\text { generated }\end{array}$ & $\begin{array}{l}\text { Grows with } \\
\text { increasing } \\
\text { mobility of } \\
\text { active routes (as } \\
\text { in ABR) }\end{array}$ & $\begin{array}{l}\text { Greater than that } \\
\text { of on-demand } \\
\text { routing }\end{array}$ \\
\hline $\begin{array}{l}\text { Quality of } \\
\text { service support }\end{array}$ & $\begin{array}{l}\text { Few can support } \\
\text { QoS, although } \\
\text { most support } \\
\text { shortest path }\end{array}$ & $\begin{array}{l}\text { Mainly shortest } \\
\text { path as the QoS } \\
\text { metric }\end{array}$ \\
\hline
\end{tabular}

In terms of metrics, comparisons [9] between the two routing protocols are: Throughput: proactive protocols perform well then reactive protocol; End to end delay: proactive protocols perform well than reactive protocols; Routing load: reactive protocols perform well than proactive protocols.

\section{DESCRIPTION OF PROTOCOLS 3.1 Destination-sequenced distance vector (DSDV) [16]}

DSDV routing protocol is the one that comes under the category of proactive routing protocol. This is a distance vector routing protocol uses the bellmann-ford algorithm. DSDV also has the feature of hop-by-hop distance vector routing protocol in which every node maintains routing table listing the "next hope" and "number of hopes" information for each possible destination in the network. The periodical broadcasts of routing updates attempt to keep the routing table completely update at all the times [1]. In the routing table each entry has sequence number specified. So, whenever a new entry in a routing table has to be obtained, then the specific protocol prefers to select the entry with the largest sequence number assigned. If these entries with the same sequence number have been obtained, then the protocol selects the metric with the lowest value assigned.

Routing information is transmitted by broadcast. The routing updates have to be transmitted periodically or immediately when any significant topology change is available to it. The specific sequence numbers [16] are assigned by destination node, which means the destination gives a sort of default even sequence number specified, and the node emitter has to send out the next update with this number specific. The data packets are exchanged from the source to destination in the network by using routing table which are stored at the each station of the network in use. The routing information [8] is advertised by broadcasting or multicasting the packets which are transmitted periodically and incrementally as topological changes are detected - for some time specified, when the stations move within the network area. The data is also kept about the length of time between arrival of the first and the arrival of best route for each destination node. The respective 
entries in the routing table may change fairly dynamically over some certain time period.

\subsection{Dynamic source routing (DSR) [17]}

DSR protocol always comes under the category of an ondemand/reactive routing protocol. This is a simple and efficient routing protocol intended specifically for use in the multi-hop wireless Ad- hoc networks of mobile nodes present. DSR [17] also allows the network to be completely of a selfassembling and a self-arrangement nature, even without the need for any existing network infrastructure or administration thereby. This routing protocol uses explicit source routing which means that every time a data packet is sent along the network, it always accommodates the list of nodes it will use to be forwarded along. This protocol allows a route to be discovered dynamically across multiple network hops to any destination in the network. The source routing means that every packet in its header contains the complete sequential list of nodes through which the packet must pass by. The two main mechanisms are used in DSR protocols which are as specified: route discovery and route maintenance. These mechanisms will work together to allow the nodes to discover and maintain the routes to random destinations in the ad-hoc network in use. The DSR protocol also has many advantages over the routing protocols like AODV, LMR, and TORA and in small to moderately sized networks also, the DSR protocol performs better than all the above mentioned routing protocols also. There is no such periodic routing of messages in DSR routing protocol, thus helps in reducing the network bandwidth overhead, also the conservation battery power and in avoiding large routing updates throughout the ad-hoc network. In this process, the data packet contains the source route in packet header and routes are stored in memory used. There is not any routing loop in this protocol. If ever there is any data packet available to send over the network, and if it has no route, then the route discovery process is initiated successfully. The route discovery process of DSR is similar to the route discovery process of the AODV protocol.

Every node that receives the route request packet in network, broadcasts it, but except for the destination node or nodes that have route to destination node in their memory along. The route through network is built by RREQ packet sent, and then the RREP packet is being routed backward to the source node. The particular route that returns RREP packet is cached on the source node for any further use. There possibly can be multiple RREP packets on one RREQ packet generated [1]. During this sending process whenever broken link is detected in the communication, the RREQ packet has been sent backward to the source node in the network. When this RREQ packet has been received source node initiates another route discovery operation for communication. The routes that always contain the broken link should be removed from the route cache information.

\subsection{Ad-hoc on demand distance vector routing protocol (AODV) [18]}

The Ad-hoc on demand distance vector routing protocol, AODV is a very effective, simple and efficient routing protocol for Mobile Ad-hoc Networks. In AODV protocol, a no fixed topology is there for mobile ad-hoc networks. This is a loop free routing protocol of MANET. It surely enables the multi-hop routing between the participating mobile nodes wishing to establish and maintain an ad-hoc network [1]. This particular routing protocol is based on the distance vector algorithm mostly. This specific algorithm uses many different messages to discover and maintain links over the network.
Whenever any particular node wants to try and find a route to another node it broadcasts a Route Request (RREQ) to all its neighbours in the network. The RREQ always passes through the network until it reaches the destination or the node with a fresh enough route to the destination node in the network. Then that particular route is made available by uncasing a RREP back to the source node in the network. This specific algorithm uses the hello messages, which is a special case of RREP message that are broadcasted periodically to the immediate neighbours. These kinds of hello messages [8] are local advertisements for the continued presence of the nodes in the network and the neighbours also using routes through the broadcasting node will continue to mark the routes as almost valid. If the hello messages anytime stop coming from a particular node over the network, then the neighbour can assume that the node has moved away and mark that link to the node as broken and notify the affected set of nodes by sending a link failure notification, which is also a special RREP case, to that set of nodes in the network.

\section{COMPARISON AMONG PROTOCOLS}

The comparison [12][2][13] among these routing protocols is mentioned in the table 4.1.

Table 4.1: Comparison among protocols on the basis of general properties

\begin{tabular}{|c|c|c|c|}
\hline Properties & DSDV & DSR & AODV \\
\hline $\begin{array}{l}\text { Route } \\
\text { acquisition }\end{array}$ & $\begin{array}{l}\text { Computed a } \\
\text { priori }\end{array}$ & $\begin{array}{l}\text { On } \\
\text { demand }\end{array}$ & On demand \\
\hline $\begin{array}{ll}\text { Flood for } \\
\text { route } \\
\text { discovery }\end{array}$ & No & Yes & Yes \\
\hline $\begin{array}{l}\text { Delay for } \\
\text { route } \\
\text { discovery }\end{array}$ & No & Yes & Yes \\
\hline $\begin{array}{l}\text { Route } \\
\text { selection }\end{array}$ & Link state & $\begin{array}{l}\text { Shortest } \\
\text { path }\end{array}$ & $\begin{array}{l}\text { Shortest } \\
\text { path }\end{array}$ \\
\hline Loop free & Yes & Yes & Yes \\
\hline Channel & Single & Single & Single \\
\hline Multiple roots & No & Yes & No \\
\hline Topology & Full & Full & Full \\
\hline Distributed & Yes & Yes & Yes \\
\hline $\begin{array}{l}\text { Uni/non-uni } \\
\text { protocol }\end{array}$ & Uniform & Uniform & Uniform \\
\hline $\begin{array}{l}\text { Unidirectional } \\
\text { link support }\end{array}$ & No & Yes & No \\
\hline Broadcast & Full & Full & Full \\
\hline
\end{tabular}




\begin{tabular}{|c|c|c|c|}
\hline QoS Support & No & No & No \\
\hline $\begin{array}{l}\text { Routing } \\
\text { philosophy }\end{array}$ & Proactive & Reactive & Reactive \\
\hline Multicast & No & No & Yes \\
\hline $\begin{array}{l}\text { Route } \\
\text { computation }\end{array}$ & Distributed & Broadcast & Broadcast \\
\hline Security & No & No & No \\
\hline Structure & Flat & Flat & Flat \\
\hline $\begin{array}{l}\text { Power } \\
\text { conservation }\end{array}$ & No & No & No \\
\hline Routes & Single & Multiple & Multiple \\
\hline $\begin{array}{l}\text { Source } \\
\text { routing }\end{array}$ & No & Yes & No \\
\hline Update & Hybrid & $\begin{array}{l}\text { Event } \\
\text { driven }\end{array}$ & $\begin{array}{l}\text { Event } \\
\text { driven }\end{array}$ \\
\hline $\begin{array}{l}\text { Periodic } \\
\text { Broadcasts }\end{array}$ & Yes & No & Yes \\
\hline $\begin{array}{l}\text { Update } \\
\text { information }\end{array}$ & $\begin{array}{l}\text { Distance } \\
\text { Vector }\end{array}$ & $\begin{array}{l}\text { Route } \\
\text { error }\end{array}$ & Route error \\
\hline $\begin{array}{l}\text { Requires } \\
\text { reliable data }\end{array}$ & No & $\mathrm{NO}$ & No \\
\hline $\begin{array}{l}\text { Update } \\
\text { destination }\end{array}$ & Neighbours & Source & Source \\
\hline Method & Broadcast & Unicast & Unicast \\
\hline $\begin{array}{ll}\text { Upon } & \text { route } \\
\text { failure } & \end{array}$ & $\begin{array}{l}\text { Floods route } \\
\text { updates } \\
\text { throughout } \\
\text { network }\end{array}$ & $\begin{array}{l}\text { Route } \\
\text { error } \\
\text { propagated } \\
\text { up to the } \\
\text { source }\end{array}$ & $\begin{array}{l}\text { Route error } \\
\text { broadcasted } \\
\text { to erase } \\
\text { invalid path }\end{array}$ \\
\hline
\end{tabular}

The complexity comparisons among the protocols are mentioned in the table 4.2 .

Table 4.2: Comparison among protocols on the basis of complexities

\begin{tabular}{|l|l|l|l|}
\hline Complexity & DSDV & DSR & AODV \\
\hline Time complexity & $\mathrm{O}(\mathrm{d})$ & $\mathrm{O}(2 \mathrm{~d})$ & $\mathrm{O}(2 \mathrm{~d})$ \\
\hline Storage complexity & $\mathrm{O}(\mathrm{X})$ & $\mathrm{O}(\mathrm{E})$ & $\mathrm{O}(\mathrm{E})$ \\
\hline Computational complexity & $\mathrm{O}(\mathrm{N})$ & $\mathrm{O}(2 \mathrm{~N})$ & $\mathrm{O}(2 \mathrm{~N})$ \\
\hline
\end{tabular}

Where $\mathrm{N}=$ No. of nodes in the network,

$\mathrm{A}=$ average no. of adjacent nodes,

$\mathrm{d}=$ Network diameter,

$\mathrm{Dd}=$ No. of maximum desired destinations,

$\mathrm{E}=$ Communication pairs,

$\mathrm{X}=$ No. of nodes affected by topological change.

\section{CONCLUSIONS}

In all the coming years, the topic of mobile computing will keep on flourishing, and an eventual seamless integration of MANET with other wireless networks, and also the fixed infrastructure of Internet appears to be inevitable. The Ad-hoc networking is just at the centre of the evolution towards the upcoming 4th generation wireless technology. The opportunity and importance of ad-hoc networks is being increasingly recognized by both the research and industry community, as evidenced by the flood of research activities, as well as the almost exponential growth in the Wireless LANs and Bluetooth sectors.

In this paper, certain descriptions of three routing protocols proposed for ad-hoc mobile networks is provided i.e. AODV, DSDV and DSR, as well as a comparison among these protocols based on certain properties and complexities of the protocols. A classification of these schemes according the routing strategy is also provided in this paper .i.e., table driven and on demand. A comparison of these two categories of routing protocols, highlighting their features and characteristics is also presented in this paper. As the matter of fact it is not clear that any particular algorithm or any class of algorithm is the best for all scenarios, since each protocol has definite advantages and disadvantages and has certain situations, which it is well suited for. This respective field of ad-hoc mobile networks is rapidly growing and challenging and due to the dynamically changing topology and infrastructure less property of its nature, secure and energy efficient routing is hard to achieve in mobile ad-hoc networks. Therefore, an attempt will be made to compare these protocols in our future research work on the basis of energy efficiency using certain metrics, so that a specific energy efficient routing protocol could be selected for research purposes.

\section{REFERENCES}

[1] Gupta, R. (2013).Ad-Hoc Routing Protocol "Review Paper". Journal of Global Research in Computer Science, 4(5), pp. 26-29

[2] Reddy, K. R., Raju, S. V., \& Venkatadri, N. (2012).Reactive, Proactive MANET Routing Protocol Comparison. International Journal of Video \& Image Processing \& Network Security, 12(5), pp. 22-27

[3] Shivahare, B.D., Wahi, C., \& Shivhare, S. (2012).Comparison of Proactive and Reactive Routing Protocols in Mobile Ad-hoc Networks using Routing Protocol Property. International Journal of Emerging Technology and Advanced Engineering, 2(3), pp. 356359

[4] Aujla, G.S., \& Kang, S.S. (2013).Comprehensive Evaluation of AODV, DSR, GRP, OLSR and TORA Routing Protocols with varying number of nodes and traffic applications over MANETs. IOSR Journal of Computer Engineering, 9(2), pp. 54-61

[5] Xue, Y., \& Nahrstedt, K. (2003).Fault-tolerant routing in mobile ad hoc networks, IEEE, pp. 1174-1179

[6] Royer, E.M., \& Toh, C.K. (1999).A review of current routing protocols for ad-hoc mobile wireless networks. IEEE Personal Communications Magazine, pp. 46-55 
[7] Grover, D. \& Singh, G. (2012).Review of routing protocols in MANET. International Journal of Computer Application, 5(2), pp. 42-50

[8] Patil, V. P. (2012).Reactive and Proactive Routing Protocol Energy Efficiency Performance Analysis in Wireless Ad-Hoc Network. International Journal of Electronics and Computer Science Engineering, 1(04), pp. 2333-2343

[9] Jayakumar, G., \& Gopinath, G. (2007).Ad Hoc Mobile Wireless Networks Routing Protocols--A Review. Journal of Computer science, 3(8), pp. 574-582

[10] Khiavi, M. V., Jamali, S., \& Gudakahriz, S. J. (2012).Performance Comparison of AODV, DSDV, DSR and TORA Routing Protocols in MANETs. International Research Journal of Applied and Basic Sciences, 3(7), pp. 1429-1436

[11] Chitkara, M., \& Ahmad, M. W. (2014). Review on MANET: Characteristics, Challenges, Imperatives and Routing Protocols. International Journal of Computer Science and Mobile Computing, 3(2), pp. 432-437

[12] Singh, T. P., Singh, R. K., \& Vats, J. (2011).Effect of Quality Parameters on Energy Efficient Routing
Protocols in MANETs. International Journal on Computer Science \& Engineering, 3(7), pp. 2620-2626.

[13] de Morais Cordeiro, C., \& Agrawal, D.P. (2002) Mobile Ad Hoc Networking. Center for Distributed and Mobile Computing, ECECS, University of Cincinnati, pp. 1-63

[14] Makkar, A., Bhushan, B., Shelja , \& Taneja, S. (2011).Behavioural study of MANET Routing Protocols. International Journal of Innovation, Management and Technology, Singapore, 2(3), pp. 210216

[15] Trung, H. D., Benjapolakul, W., \& Duc, P. M. (2007).Performance evaluation and comparison of different ad hoc routing protocols. Computer Communications, 30(11), pp. 2478-2496

[16] Perkins, C. E., \& Bhagwat, P. (1994).Highly dynamic destination-sequenced distance-vector routing (DSDV) for mobile computers. In ACM SIGCOMM Computer Communication Review, ACM, 24(4), pp. 234-244

[17] Johnson, D. B., \& Maltz, D. A. (1996).Dynamic source routing in ad hoc wireless networks. In Mobile computing, Springer US, 353, pp. 153-181

[18] NWG, "Ad-hoc On Demand Distance Vector Routing (AODV)”, http://tools.ietf.org/pdf/rfc3561.pdf. 